\title{
Giant splenic abscess caused by Salmonella enterica
}

\author{
Francesk Mulita ${ }^{1}$, Elias Liolis ${ }^{1}$, Levan Tchabashvili ${ }^{1}$, Fotis Iliopoulos ${ }^{1}$, Nikolas Drakos ${ }^{1}$, \\ Ioannis Maroulis ${ }^{1}$, and Michail Vailas ${ }^{1}$ \\ ${ }^{1}$ University General Hospital of Patras Holy Mary the Help
}

January 29, 2021

\begin{abstract}
A 14-year-old boy presented to our Emergency Department complaining of fever, and abdominal pain. An abdominal computed tomography showed a large abscess of the spleen. Percutaneous aspiration of the lesion was performed. Splenectomy was performed 38 days after percutaneous aspiration because of the abscess's considerable size.
\end{abstract}

CLINICAL IMAGE

Giant splenic abscess caused by Salmonella enterica

Francesk Mulita $^{1}$, Elias Liolis ${ }^{2}$, Levan Tchabashvili ${ }^{1}$, Fotios Iliopoulos ${ }^{1}$, Nikolas Drakos $^{1}$, Ioannis Maroulis ${ }^{1}$ and Michail Vailas ${ }^{1}$

${ }^{1}$ Department of General Surgery, General University Hospital of Patras, Greece

${ }^{2}$ Department of Internal Medicine, General University Hospital of Patras, Greece

Correspondence: Francesk Mulita MD, MSc, $\mathrm{PhD}(\mathrm{c})$, Resident Surgeon at the Department of Surgery, General University Hospital of Patras, Achaia, Greece, Tel.: +30 6982785142; E-mail: oknarfmulita@hotmail.com; ORCID Id: https://orcid.org/0000-0001-7198-2628

\section{Key Clinical Message}

Splenectomy is the gold standard for treating a splenic abscess, when percutaneous drainage fails or is less likely to be successful.

\section{Case Description}

A 14-year-old boy with free medical history and no surgical intervention was admitted to our hospital with high-grade fever, and abdominal pain lasting for 4 days. On examination, the patient's temperature was 39, heart rate was 105 beats per minute, blood pressure was 110/70 and respiratory rate was 12 breaths per minute. His abdomen was soft, without distension and only mild tenderness in the upper left quadrant was found. The initial white blood cells were $11.77 \mathrm{~K} / \mu \mathrm{l}$, and C-reactive protein level was $20.8 \mathrm{U} / \mathrm{l}$. Liver and renal function test and serum amylase were normal. A computed tomography (CT) of the abdomen showed a large abscess of the spleen, of an average size of $13 \mathrm{~cm} \times 9 \mathrm{~cm}$ (Figure 1 ).

Empirical treatment with meropenem and vancomycin was started, and percutaneous aspiration of the lesion was performed under CT guidance. The material was sent for culture, which led to the development of Salmonella enterica. Splenectomy was performed 38 days after percutaneous aspiration because of abscess's considerable size. The operation was completed successfully. The spleen weighed $362 \mathrm{~g}$. Histopathology revealed a giant splenic epidermoid cyst with a wall consisting of fibrous tissue and accumulation of necrotic tissue. 
Abscess of the spleen is a very rare clinical problem, and carries very high mortality reaching more than $70 \%$, if the diagnosis is missed [1]. According to the literature, treatment of splenic abscess includes conservative measures as well as surgical intervention. In children and in cases of solitary abscesses with a thick wall, percutaneous aspiration may be performed. Otherwise, splenectomy is the preferred approach in most cases. However, treatment should be customized for each patient [2].

Keywords: Splenectomy, splenic abscess, Salmonella enterica, percutaneous drainage

\section{Patient consent for publication}

A written informed consent was obtained from the patient for publication of this case report.

\section{Conflict of interest}

There are no conflicts of interest to declare.

\section{Financial support and sponsorship}

None

\section{Author contribution}

FM, EL, LT, FI and ND: contributed to the clinical data collection and prepared the case report. FM, IM and MV: contributed to the design of the case report presentation and performed the final revision of the manuscript.

\section{Data availability}

Data available on request from the authors

\section{References}

Lee MC, Lee CM. Splenic Abscess: An Uncommon Entity with Potentially Life-Threatening Evolution. Can J Infect Dis Med Microbiol . 2018;2018:8610657. Published 2018 Jan 31. doi:10.1155/2018/8610657

Lee WS, Choi ST, Kim KK. Splenic abscess: a single institution study and review of the literature. Yonsei Med J . 2011;52(2):288-292. doi:10.3349/ymj.2011.52.2.288 


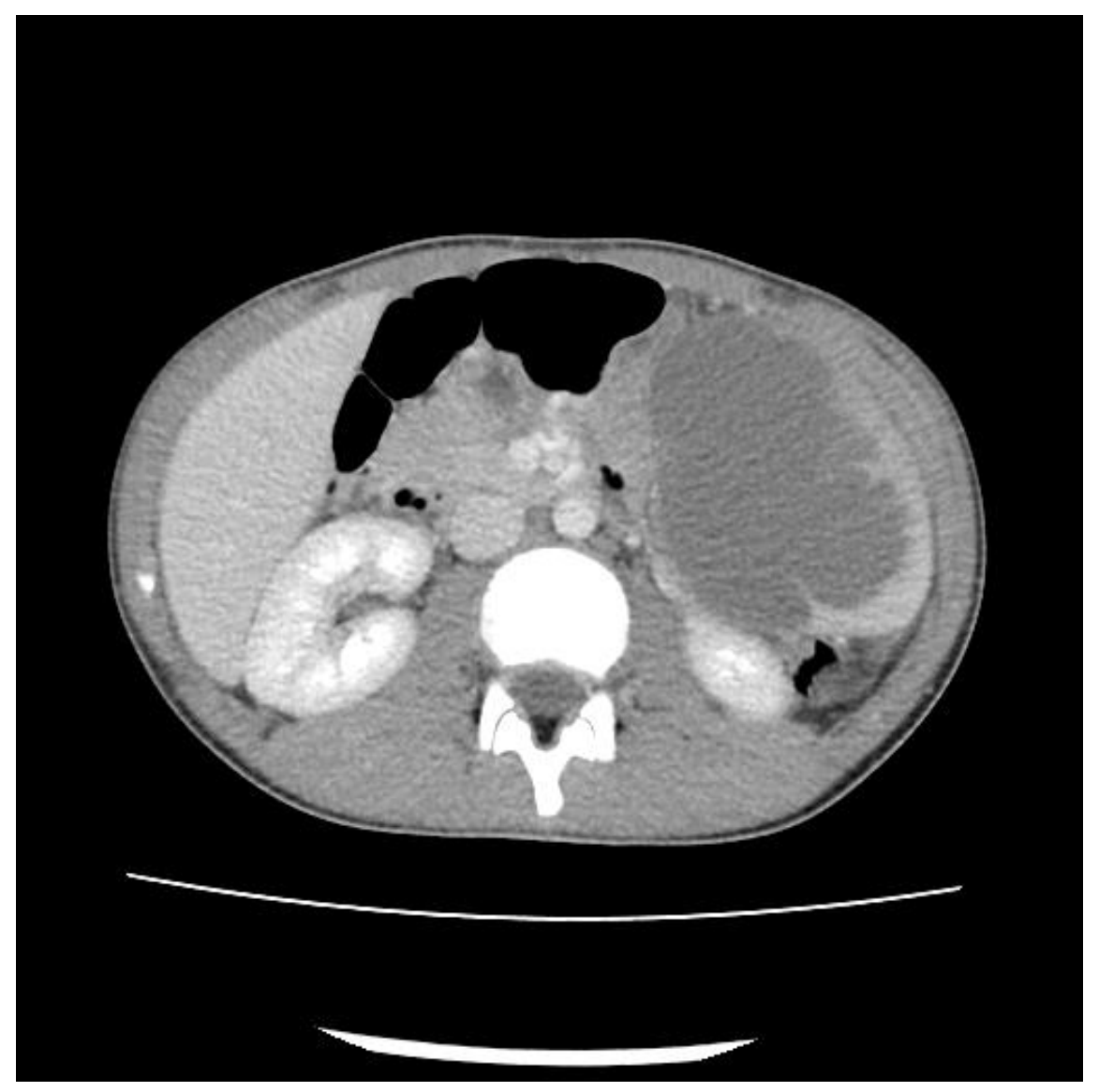

Figure 1. Abdominal CT scan of a 14-year-old boy. The spleen contained a large single abscess of $13 \mathrm{~cm}$ $\times 9 \mathrm{~cm}$. 


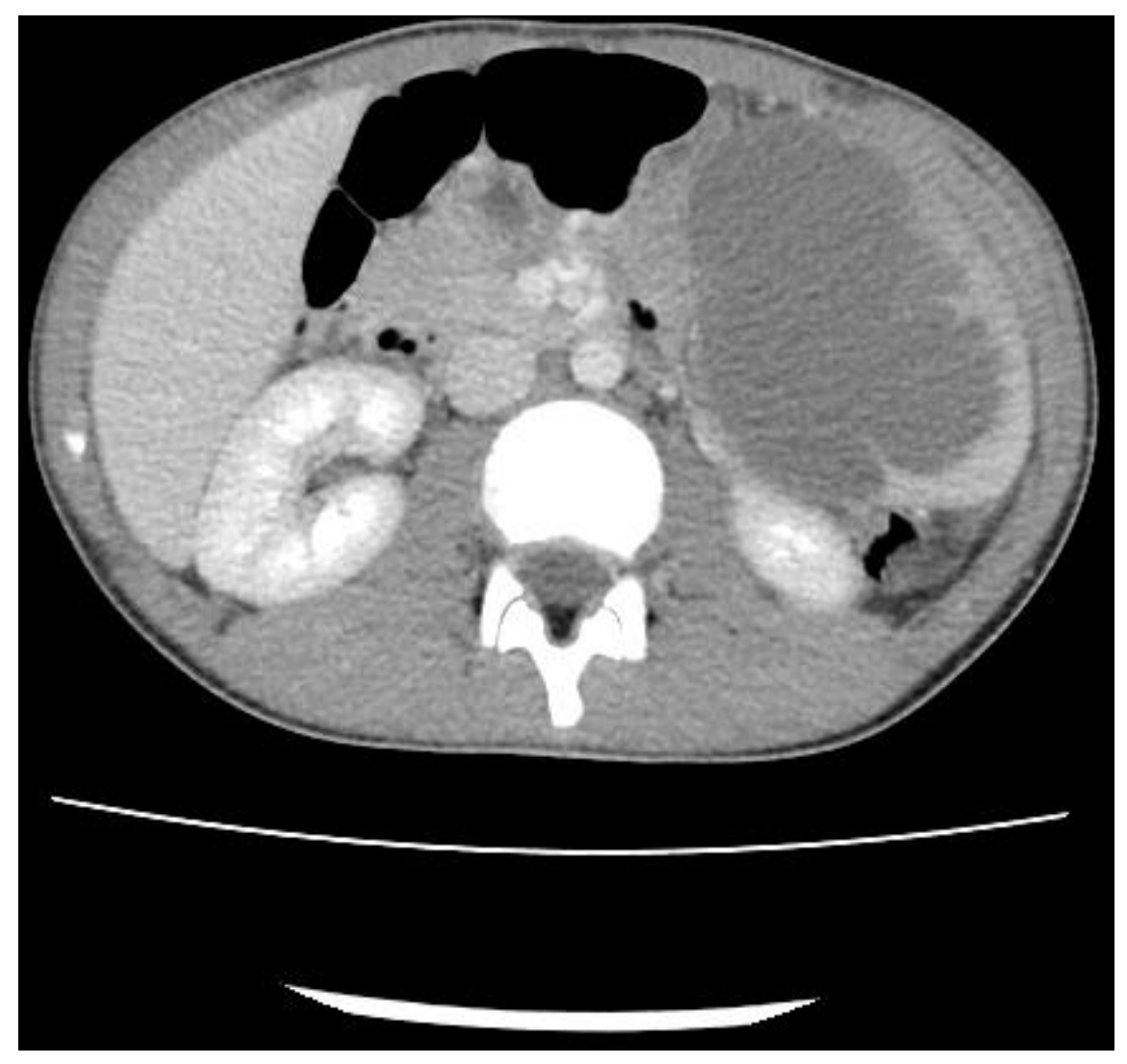

